\title{
Trefoil factor 3 (TFF3) from human breast milk activates PAR-2 receptors, of the intestinal epithelial cells HT-29, regulating cytokines and defensins
}

\author{
Barrera Roa GJ, Sanchez Tortolero G \\ Laboratorio de Biotecnología Aplicada L.B.A., Av. Don Julio Centeno, San Diego, Venezuela. \\ girolamobarrera@hotmail.com
}

\begin{abstract}
Trefoil factors are effector molecules in gastrointestinal tract physiology. Each one improves healing of the gastrointestinal tract. Trefoil factors may be grouped into three classes: the gastric peptides (TFF1), spasmolytic peptide (TFF2) and intestinal trefoil factor (TFF3). Significant amounts of TFF3 are present in human breast milk. Previously, we have reported that trefoil factor 3 isolated from human breast milk produces down regulation of cytokines and promotes human beta defensins expression in intestinal epithelial cells. This study aimed to determine the molecular mechanism involved. Here we showed that the presence of TFF3 strongly correlated with protease activated receptors 2 (PAR-2) activation in human intestinal cells. Intracellular calcium (( $\left.\left.\mathrm{Ca}^{2+}\right) \mathrm{i}\right)$ mobilization was induced by the treatment with: 1) TFF3, 2) synthetic PAR-2 agonist peptide. The co-treatment with a synthetic PAR-2 antagonist peptide and TFF3 eliminates the latter's effect. Additionally, we demonstrated the existence of interactions among TFF3 and PAR-2 receptors through far Western blot and co-precipitation. Finally, down regulation of PAR-2 by siRNA resulted in a decrease of TFF3 induced intracellular $\left(\mathrm{Ca}^{2+}\right)$ i mobilization, cytokine regulation and defensins expression. These findings suggest that TFF3 activates intestinal cells through PAR-2 (Fig. 4, Ref. 19). Text in PDF www.elis.sk.

KEY WORDS: breast milk, trefoil factor family TFF, protease-activated receptor 2 PAR-2, defensins, cytokines.
\end{abstract}

\section{Introduction}

Human breast milk provides nutrients and bio-active factors that may modulate growth and development of the neonate gastrointestinal tract (1). Human milk constitutes a good source to isolate bio-active peptides and proteins that have been proved to have a favorable role on gut development and immune function (2). Colostrum and mature-milk contain immunoglobulin A( $\operatorname{sg} \mathrm{A}$ ), antimicrobial peptides such as defensins, cytokines, and trefoil factors (TFFs). The three main trefoil factors are TFF1, TFF2 and TFF3. Every one of them play a significant role in the conservation and healing of human gastrointestinal tract. Previously we have reported that TFF3 isolated from breast milk produces down regulation of cytokines and defensins $(3,4)$. This study aimed to determine the molecular mechanism involved in this process. It has been hypothesized that TFF3 has no specific receptor. Other data indicates that intestinal trefoil factor (ITF) can bind to specific cell surface proteins and exert biological effects $(5,6)$. In this sense, we tested the involvement of protease activated receptors (PARs)

Laboratorio de Biotecnología Aplicada L.B.A., Av. Don Julio Centeno, San Diego, Venezuela, Apartado 2001

Address for correspondence: G.J. Barrera Roa, Laboratorio de Biotecnología Aplicada L.B.A., Av. Don Julio Centeno, San Diego, Venezuela, Apartado 2001.

Phone: +58.412.5071616, Fax: +58.245.5640380 in human TFF3 signaling. PARs are integral membrane proteins that are activated by specific cleavage of the amino terminal sequence that exposes a new $\mathrm{N}$-terminal sequence functions as a tethered ligand that binds intra-molecularly to activate the receptor (7). Although the proteolysisis is the main mechanism for PAR activation, it is well known that a synthetic peptide (SLIGKV) that mimics the new N-terminal sequence produced after the cleavage, activates PAR-2 receptors without its proteolytic processing (7). In this sense, here we report that TFF3 isolated from human breast milk activated PAR-2 receptors of intestinal epithelial cells HT-29.

\section{Materials and methods}

\section{Human milk collection}

Samples of breast milk were collected within 2-4 weeks postpartum from healthy human mothers (18-30 years old) by manual breast massage. All samples were obtained with an informed consent.

\section{Cultured cells}

The HT-29 colonic cell line (passages 5-15) was obtained from the American type of Culture Collection (ATCC, Manassas, USA) and cultured according to the supplier's instructions.

\section{Trefoil factor 3 purification}

TFF3 was isolated from human breast milk as previously reported (3). 
A
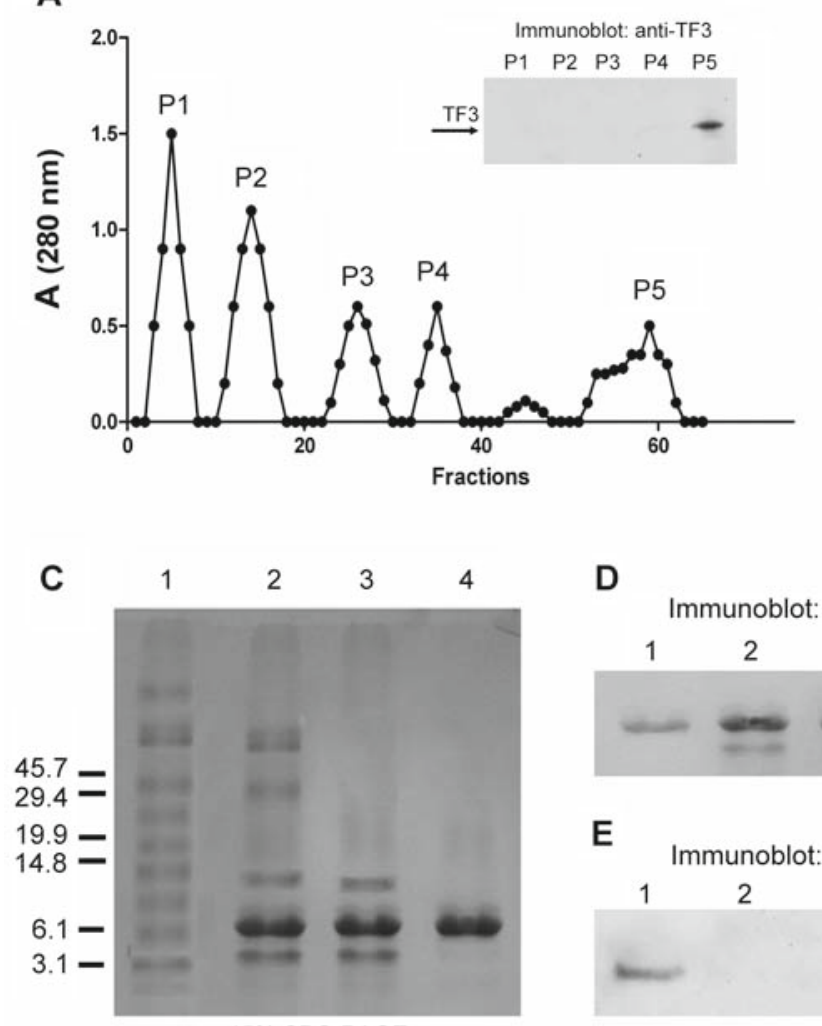

$15 \%$ SDS-PAGE
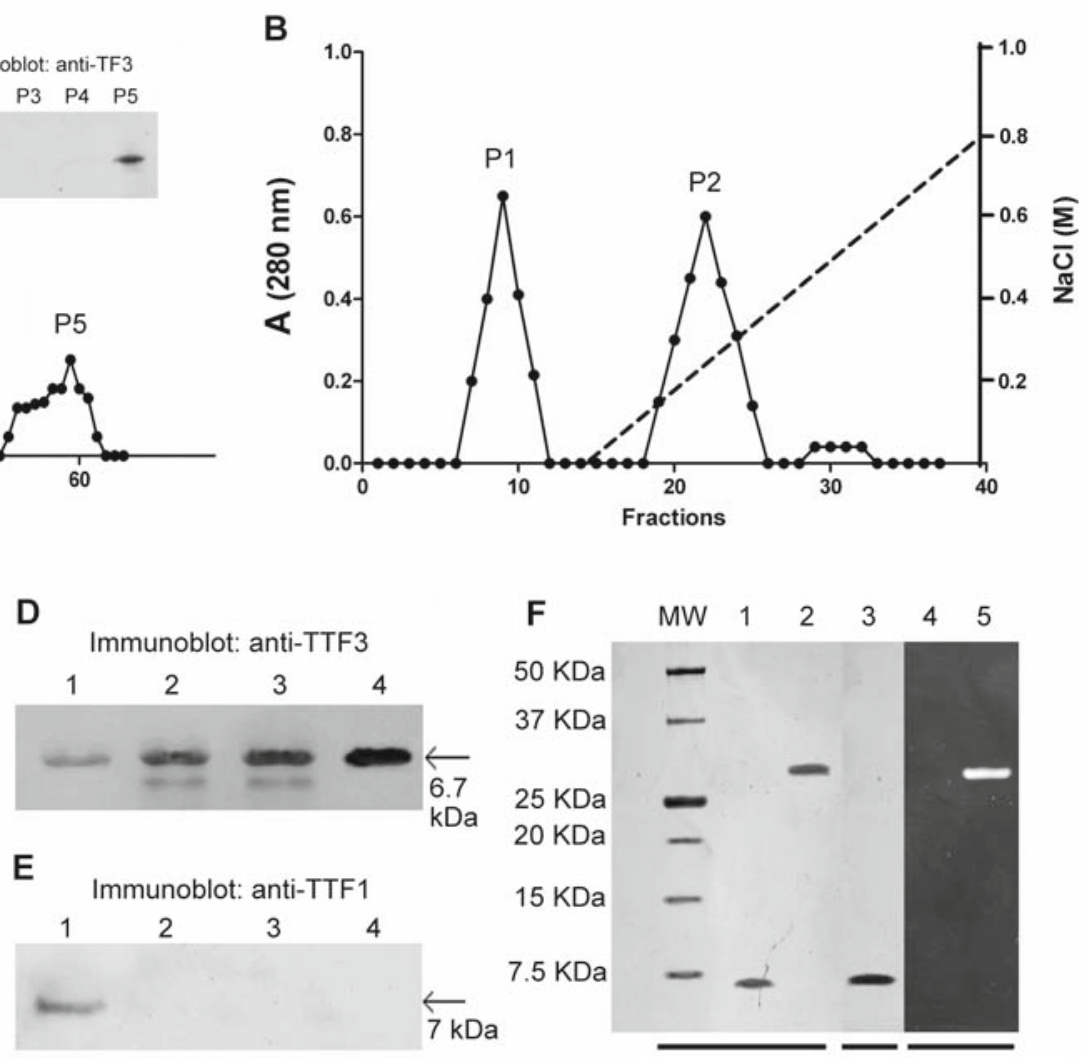

Fig. 1. Purification TFF3. (A) Gel filtration chromatography. (B) DEAE-Sepharose FF chromatography. (C) non-denaturing $15 \%$ SDS-PAGE. (D) Immunoblotting with anti-TFF3. (E) Immunoblotting with anti-TFF1. (C-E) Lane 1, total homogenate; Lane 2, $10 \mu \mathrm{g}$ of proteins obtained after isoelectric precipitation; Lane 3, $10 \mu \mathrm{g}$ of fraction "P5" obtained after gel filtration chromatography; Lane 4, $10 \mu \mathrm{g}$ of fraction "P2" obtained after DEAE chromatography. (F)TFF3 Purified (lane 1) and immunoblotting with anti-TFF3 (lane 3). Proteolytic activity of TFF3 was tested by the zymogram assay (lane 4). Trypsin as positive control in zymography analysis (lane 5).

\section{SDS-PAGE and immunoblotting}

Purified TFF3 was subjected to electrophoresis on $15 \%$ SDSPAGE and immunoblotting as previously reported (3).

Zymography analysis

$10 \mu \mathrm{g} / \mathrm{ml}$ of purified TFF3, or $5 \mu \mathrm{g} / \mathrm{ml}$ of trypsin (positive control) were subjected to SDS-PAGE $15 \%$ acrylamide separating gel containing $1 \mathrm{mg} / \mathrm{ml}$ casein, $20 \mu \mathrm{g} / \mathrm{ml} \mathrm{BSA}$, under non reducing conditions. Subsequently, gels were treated twice with $2.5 \%$ Triton X-100, rinsed with water and incubated at $37{ }^{\circ} \mathrm{C}$ for $48 \mathrm{~h}$ in $50 \mathrm{mM}$ Tris ( $\mathrm{pH} \mathrm{8.0)}, 5 \mathrm{mM} \mathrm{CaCl}_{2}$. Then, the gels were stained with Coomassie brilliant blue and de-stained in a solution of $25 \%$ ethanol and $10 \%$ acetic acid. Protease activity appeared as clear bands against a blue background.

\section{$\left(\mathrm{Ca}^{2+}\right)_{i}$ measurements}

The cytosolic $\mathrm{Ca}^{2+}$ activity $\left(\left(\mathrm{Ca}^{2+}\right) \mathrm{i}\right)$ was measured in HT29 cells using the $\mathrm{Ca}^{2+}$-sensitive fluorescent dye fura-2-AM as previously described (7). Briefly, the cells (1000 cells $/ \mathrm{ml})$ were seeded onto each cover slip and incubated for $30 \mathrm{~min}$ at $37^{\circ} \mathrm{C}$ in $1 \mathrm{ml}$ Tyrodesbuffer supplemented with $2 \mu \mathrm{M}$ fura-2-AM. In some experiments (only cells treated with RNAi), the RNAi treatment was done similarly as above except that the cells were transferred to glass-bottomed $35 \mathrm{~mm}$ cell culture dishes before treatment. Forty eight hours after RNAi treatment, the $\left(\left(\mathrm{Ca}^{2+}\right) \mathrm{i}\right)$ was loaded by the fluorescent probe fura-2-AM (7). Single-cell fluorescence measurements of $\left(\mathrm{Ca}^{2+}\right)$ i were done using an imaging system from TILL Photonics GmbH (Munich, Germany). Cells were excited alternately at 340 and $380 \mathrm{~nm}$ for $50 \mathrm{~ms}$ at each wavelength at the rate of $0.33 \mathrm{~Hz}$ and the resulting emission was collected above $510 \mathrm{~nm}$.

\section{NA-interference Assay}

siRNAs targeting PAR-2 and PAR-1 were from Santa Cruz Biotechnology (cat. No. sc-36188, and cat. No. sc-36663). HT29 cells were cultured at 250,000 cells $/ \mathrm{ml}$ in DMEM with $10 \%$ FBS in $25 \mathrm{~cm}^{2}$ Falcon culture flask, at $37{ }^{\circ} \mathrm{C}$ and $5 \% \mathrm{CO}_{2}$. After $24 \mathrm{~h}$, the monolayer reached $35-40 \%$ confluence and was then washed twice with $2 \mathrm{ml}$ of Opti-MEM supplemented with $2 \mathrm{mM}$ $\mathrm{CaCl}_{2}$ (Opti- MEM-Ca), without FBS. Cells were transfected in $6 \mathrm{ml}$ of Opti-MEM-Ca with $200 \mathrm{nM}$ of the respective synthetic siRNA oligo, employing $0.2 \%$ Lipofectamine- 2000 as transfectionagent. 


\section{Far Western-Blot}

Total cell lysate from HT-29 containing PAR-2 proteins (prey proteins) were firstly separated by $15 \%$ SDS-PAGE, and transferred to a nitrocellulose membrane. The proteins in the membrane were then denatured and renatured in AC buffer by gradually reducing the guanidine $-\mathrm{HCl}$ concentration. Membranes were washed 5 times with PBS-tween, blocked for 2 hours in $5 \%$ skim milk in PBS-Tween, and incubated with $10 \mu \mathrm{g} / \mathrm{ml}$ of TFF3 (bait protein) in binding buffer (100 mMNaCl, $20 \mathrm{mMTris}(\mathrm{pH} 7.6), 0.5 \mathrm{mM}$ EDTA, $10 \%$ glycerol, $0.1 \%$ Tween-20, $2 \%$ skim milk powder) overnight at $4{ }^{\circ} \mathrm{C}$. Bound TFF3 (bait protein) was detected by a primary antibody in a method similar to standard Immunoblotting described above (3). Membranes were stripped and were reprobed (the reprobed was done using standard immunobloting to determine the position of the PAR-2 (prey proteins) on the membrane).

\section{Co-immunoprecipitation assay}

HT-29 cells were incubated with TFF3 $(10 \mu \mathrm{g} / \mathrm{ml})$ by $2 \mathrm{~h}$ and whole cell lysates were prepared with $0.2 \mathrm{~mL}$ lysis buffer $(50$ mM Tris-HCl, pH 7.2, 150 mM NaCl, 5 mM EDTA, 0.1 mM DTT, 1 $\%$ NP-40, $10 \%$ Glycerol and protease cocktail inhibitor) at $4{ }^{\circ} \mathrm{C}$ for $30 \mathrm{~min}$. For immunoprecipitation, the lysates were incubated with $4 \mu \mathrm{g}$ of an anti-human PAR-2 antibody at RT for $2 \mathrm{~h}$, then mixed with $40 \mu \mathrm{L}$ of $50 \%$ slurry of protein G-Sepharose and incubated for an additional $2 \mathrm{~h}$. Beads were washed three times with lysis buffer and boiled with $5 \mathrm{X}$ SDS loading buffer for $10 \mathrm{~min}$. Western blot using anti-TFF3 as primary antibody was done as described above.

\section{ELISA} $(3,10)$.

We quantified hBDs and cytokines as previously reported

\section{Reverse transcription polymerase chain reaction (RT-PCR)}

RNA was extracted from HT-29 intestinal cells by TrizolTM (Invitrogen) according to the manufacturer's instructions. PCR was done as previously reported $(3,4)$.

\section{Results}

\section{Trefoil factor 3 (TFF3) purification}

Trefoilfactor 3 (TFF3) was purified from human milk by ammonium sulfate precipitation, followed by isolectric precipitation, gel filtration and DEAE-Sepharose chromatography (9) (Fig. 1A and 1B). The purity of TFF3 was confirmed by SDS-PAGE (Fig. 1C). Our TFF3 preparations contained a band with apparent mass of approximately $7 \mathrm{kDa}$. That is recognized by anti-TFF3 antibody (Fig. 1D). We obtained five main fractions in the gel filtration chromatography (Fig. 1A), each fraction was concentrated and underwent to Western blot analysis, just the fifth fraction (P5) contained the Trefoilfactor 3 (Fig. 1A, insert). Then, the P5 fraction (Fig. 1A) was concentrated and loaded in DEAE-Sepharose chromatography (Fig. 1B). After elution with $\mathrm{NaCl}$, the $\mathrm{P} 2$ fraction contained the Trefoilfactor 3 purified. Additionally, we tested by immunoblot our TFF3 preparations with an anti-human TFF1 (Fig. 1E). TFF1 was detected just in clarified human breast milk (total homogenate, lane 1). The proteolytic activity of isolated peptide was analyzed by case in zymography analysis (Fig. 1F, lane 4). We found that the band observed by SDS-PAGE and immunoblot corresponded to TFF3 purified without proteolytic activity. Finally, we used trypsin as positive control in zymography analysis (Fig. 1F, lane 5). Together, the results demonstrate that TFF3 was purified from human breast milk without proteolytic activity.

\section{Secreted-TFF3 activates PAR-2 in HT-29 cells}

To evaluate the effect of TFF3 on PAR-2 activation, we explored the epithelial cell response by measuring intracellular $\mathrm{Ca}^{2+}$ mobilization after exposure of TFF3 or specific PAR-2 agonist peptide. As indicated in Figure 2, both, PAR-2agonist peptide (200 $\mu \mathrm{M}$, positive control) and TFF3 $(10 \mu \mathrm{g} / \mathrm{ml})$ purified from human breast milk induced a rapid increase in intracellular $\left(\mathrm{Ca}^{2+}\right)$ in HT-29 intestinal epithelial cells (Fig. 2A and 2B). In addition, the treatment with either PAR-2 scrambled agonist peptide (200 $\mu \mathrm{M}$, negative control) or TFF3 vehicle (Tris- $\mathrm{HCl} 50 \mathrm{mM}, \mathrm{pH} 7.2$ ) did not modified the intracellular calcium levels (Fig. 2C and 2D). Finally, an analogue of the PAR-2-activating peptide (FSLLRY) has been described to inhibit trypsin-induced activation of PAR-2 $(11,12$,). Therefore, to confirm the response of PAR-2 to TFF3, we tested regardless the PAR-2 antagonist peptide FSLLRY inhibits the activation of PAR-2 by agonist or TFF3. In our hands, the PAR-2 agonist peptide response was completely inhibited by FSLLRY (200 $\mu \mathrm{M}$, Fig. 2E), confirming that it acts as an effective PAR-2 antagonist on intestinal epithelial cells. This antagonist peptide, FSLLRY $(200 \mu \mathrm{M})$ blocked the response to TFF3 $(10 \mu \mathrm{g} /$ $\mathrm{ml}$ ) (Fig. 2F), indicating that the variations in $\left(\mathrm{Ca}^{2+}\right) \mathrm{i}$ induced by the TFF3 are due to the activation of PAR-2 in epithelial cells.

It is known that intestinal cells HT-29 express other PARs receptors such as PAR-1 (thrombin receptor) (16). In this sense, we evaluated whether intestinal cells (HT-29) can raise their $\left(\mathrm{Ca}^{2+}\right) \mathrm{i}$ after PAR-2 depletion or under the action of PAR-2 antagonist peptide. As indicated in Figure 2, Thrombin ( $20 \mathrm{nM}$, positive control) induced a rapid increase of intracellular $\left(\mathrm{Ca}^{2+}\right)$ in HT-29 cells (Fig. $2 \mathrm{G}$ ) and HT-29 cells pre-treated with PAR-2 antagonist peptide (200 $\mu \mathrm{M})$. Taken together, these results suggested that intestinal epithelial cells responded to TFF3 by activation of PAR-2 receptor. Finally, to determine the role of G proteins in TFF3 mediated PAR-2 activation, HT-29 cells were pretreated with pertussis toxin (PTX) to uncouple PAR-2 from PTX-sensitive G proteins (7). PTX pretreatment prevented the increases in $\left(\mathrm{Ca}^{2+}\right) \mathrm{i}$ induced by the fragments (Fig. 2H). Thus, PTX-sensitive G proteins are critically involved in mediating the activation of PAR-2 by TFF3. Taken together, these results showed that the TFF3 fragments, obtained from human milk, activated PAR-2 receptors in HT-29 intestinal epithelial cells.

PAR-2 knockdown inhibits TFF3-induced intracellular calcium mobilization in intestinal epithelial cells HT-29

Previous studies have reported that intestinal epithelial cells HT-29 endogenously express PAR-2 receptors (13). To confirm the involvement of PAR-2 in TFF3-stimulated intracellular calcium mobilization, HT-29 cells were treated with RNA interference (siRNA) (Santa Cruz Biotechnology, cat. No. sc-36188) to 

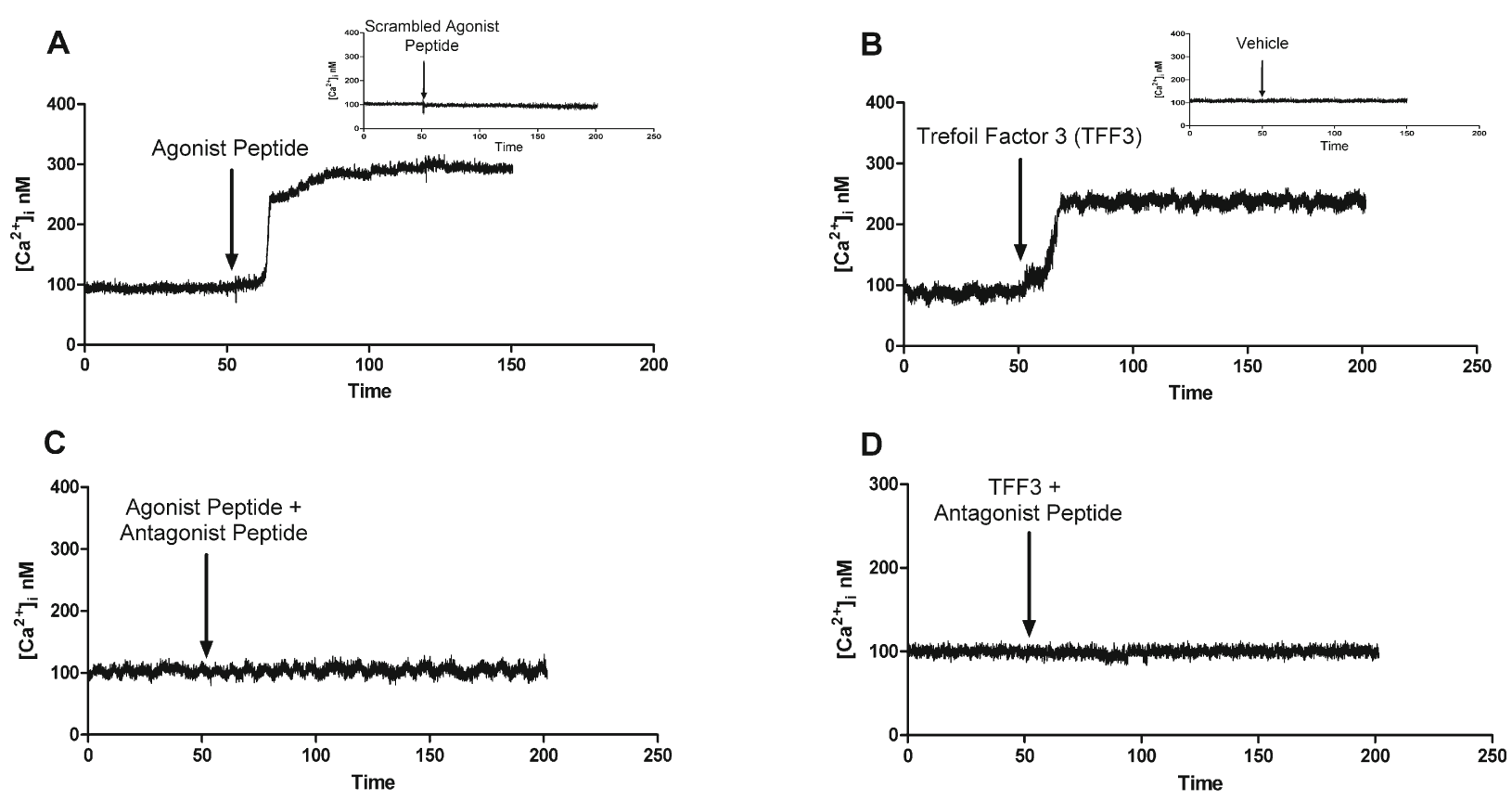

$\mathbf{E}$

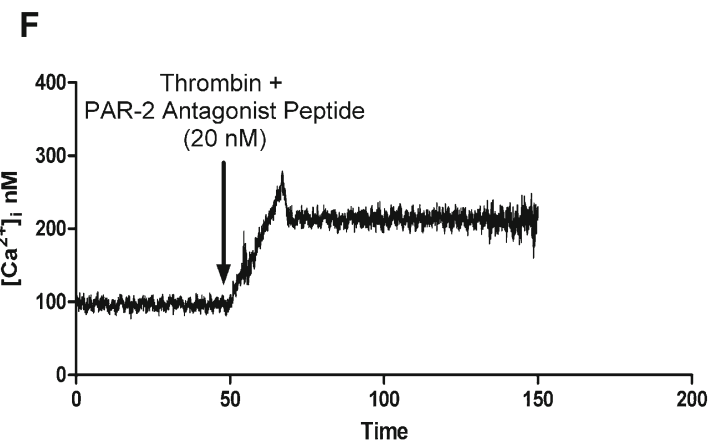

G

H
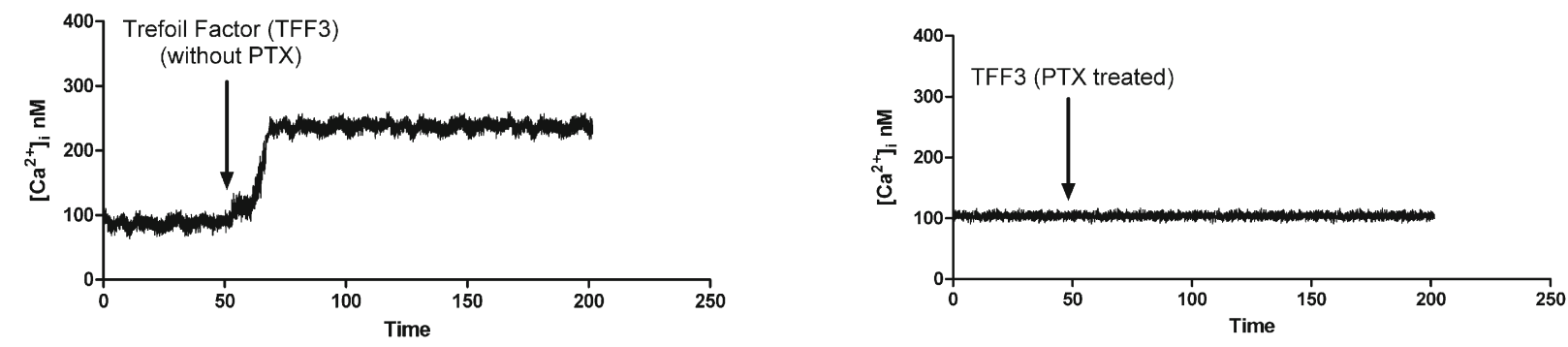

Fig. 2. PAR-2 activation by TFF3. HT-29 cells were treated with: (A) PAR-2 agonist peptide (200 $\mu$ M, positive control), (Insert) PAR-2 scrambled agonist peptide (200 $\mu \mathrm{M}$, negative control), (B) TFF3 isolated from human breast milk (10 $\mu \mathrm{g} / \mathrm{ml})$, (insert) TFF3 vehicle (Tris-HCl $50 \mathrm{mM}$, pH 7.2, negative control), (C) PAR-2 agonist peptide response was completely inhibited by FSLLRY (200 $\mu$ M, PAR-2 antagonist peptide). This antagonist peptide, FSLLRY $(200 \mu \mathrm{M})$ blocked the response to TFF3 $(10 \mu \mathrm{g} / \mathrm{ml})(\mathrm{D})$ ). Additional positive controls are shown: (E) Thrombin $(20 \mathrm{nM}$, enzyme that activates PAR-1), and Trombin $(20 \mathrm{nM})$ in cells pre-treated with $200 \mu M$ PAR-2 antagonist peptide (F), cells were preincubated 4 $\mathrm{h}$ with $1 \mu \mathrm{g} / \mathrm{ml}$ of PTX, as indicated $(\mathrm{H})$ and without PTX $(\mathrm{G})$. Traces shown represents at least 10 traces obtained on 4 separate preparations.

produce specific knockdown of PAR-2 receptors. We tested two siRNA concentrations ( 50 or $200 \mathrm{nM}$ ). In this work, we showed that 200 nMof siRNA producedan efficient knockdown of PAR2 receptors evaluated by RT-PCR (Fig. 3B, lane 4), densitometry analysis (Fig. 3C) and Western blot (Fig. 3D, lane 4). Compared with HT-29 cells transfected with control siRNA, cells transfected with the selective siRNA against PAR-2 showed a significant inhibition of the intracellular calcium mobilization stimulated by 
A

\begin{tabular}{lcccc} 
CDNA & Forward primer & Reverse primer & $\begin{array}{c}\text { Annealing } \\
\text { temperature }\end{array}$ & $\begin{array}{c}\text { PCR-product } \\
\text { size }\end{array}$ \\
\hline PAR-2 & 5'-GGCCAATCTGGCCTTGGCTGAC-3' & 5'-GGGCAGGAATGAAGATGGTCTGC-3' & $62^{\circ} \mathrm{C}$ & $320 \mathrm{bp}$ \\
b-actin & 5'-ACATCCGCAAAGACCTCTACG -3' & 5'-TTGCTGATCCACATCTGCTGG-3' & $55^{\circ} \mathrm{C}$ & $250 \mathrm{bp}$
\end{tabular}

B

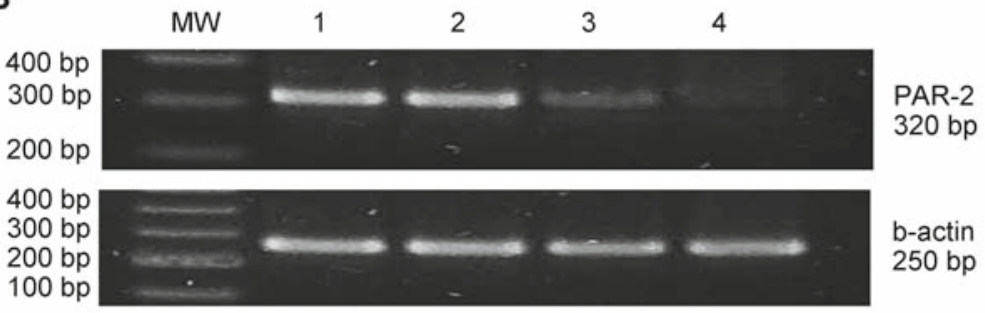

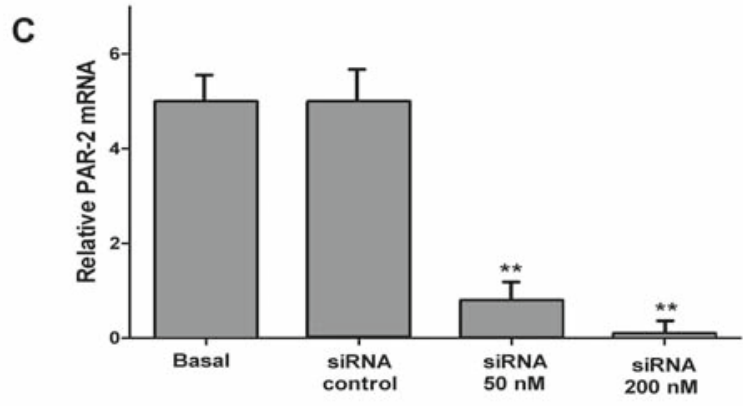

E

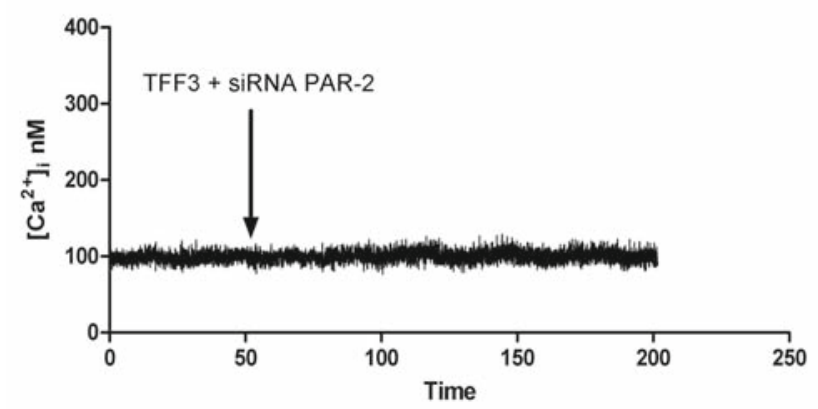

D

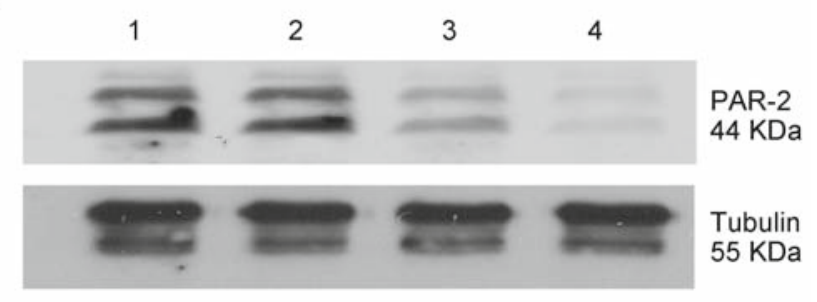

$\mathbf{F}$

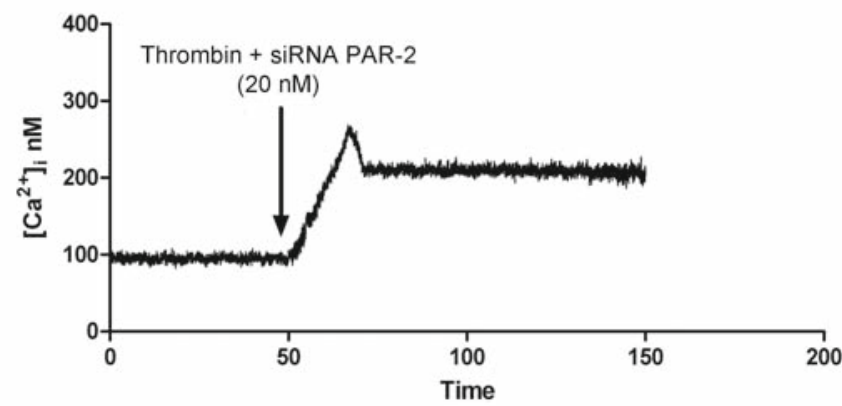

Fig. 3. PAR-2 knockdown by siRNA. (A) Specific primers and annealing temperatures employed. (B) RT-PCRs for PAR-2 and $\beta$-actin were carried out from cell culture samples divided in four groups: Basal (lane 1), cells treated with Irrelevant scrambled siRNA (lane 2, negative control), cells treated with PAR-2 siRNA at $50 \mathrm{nM}$ (lane 3) or $200 \mathrm{nM}$ (lane 4), densitometric analysis of DNA bands (C), Western blot using anti-PAR-2 to confirm that PAR-2 was knock-down (upper panel) and Western blot (D) using anti-Tubulin as positive control (lower panel). Finally, HT-29 cells pre-treated with 200 nM PAR-2 siRNA were loaded with $2 \mu$ M fura-2-AM in Tyrodes buffer. Loaded cells were treated with TFF3 $(10 \mu \mathrm{g} / \mathrm{ml})$, as indicated in (E) or Thrombin $(20 \mathrm{nM}$, positive control) indicated in (F). Traces shown represents at least 10 traces obtained on 4 separate preparations.

TFF3 (Fig. 3E). Finally, HT-29 cells pre-incubated with 200nMof PAR-2 siRNA were treated with thrombin (positive control, 20 $\mathrm{nM})$ in order to verify that HT-29 cells can raise their $\left(\mathrm{Ca}^{2+}\right) \mathrm{i}$ after PAR-2 depletion (Fig. 3F). These results suggested that PAR-2 was involved in TFF3-induced intracellular signaling of HT-29 cells.
PAR2 knockdown inhibits the down regulation of cytokines (IL8 and IL6) and defensins expression ( $h B D 2$ and hBD4) induced by TFF3

Previously, we have reported that Trefoilfactor 3 isolated from human breast milk produce down regulation of cytokines (IL-8 
A

AR-2

(44 KDa)

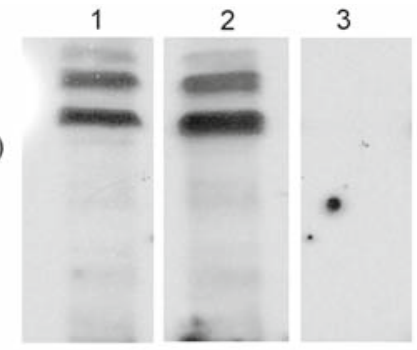

B
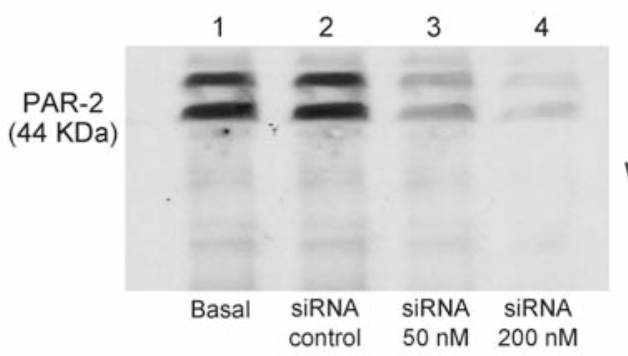

C

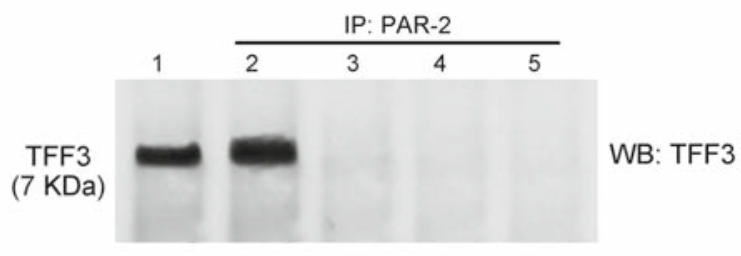

WB: TFF3
D

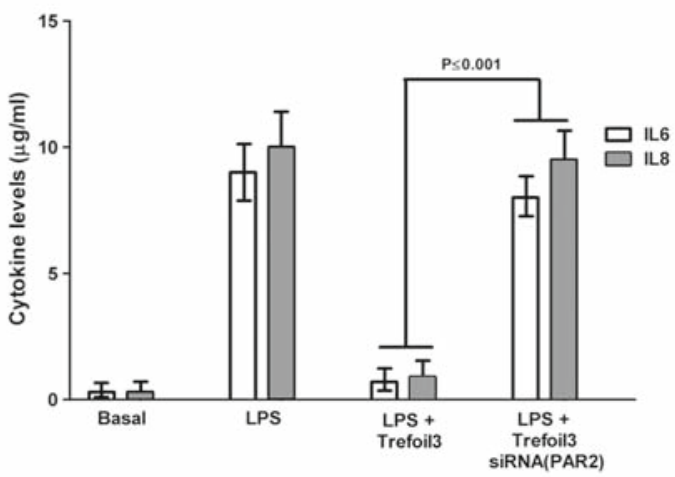

E

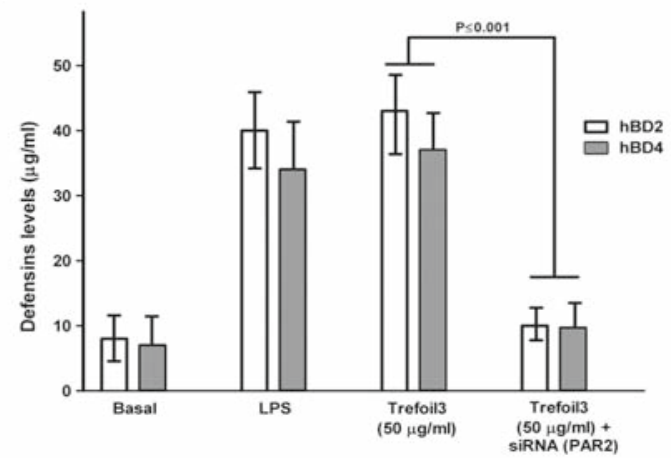

Fig. 4. Far Western and co-immunoprecipitation. (A) HT-29 Plasma membranes proteins were denatured, renatured, blocked, and incubated with purified TFF3 $(10 \mu \mathrm{g} / \mathrm{ml})$ overnight at $4^{\circ} \mathrm{C}$. Bound TFF3 was detected by immunoblotting using anti-TFF3 (lane 1). Then, membranes were stripped and reprobed using standard immunoblotting to determine the PAR-2 on the membrane (lane 2). Finally, it was tested if primary antibody anti-TFF3 binds nonspecifically to cell lysate from HT-29 through Western blot assay (lane 3). Additionally, far Western blot assay in cells treated with PAR-2 siRNA was done (B). Basal expression levels (lane 1), cells treated with irrelevant scrambled siRNA (lane 2), cells treated with PAR-2 siRNA at $50 \mathrm{nM}$ (lane 3) or $200 \mathrm{nM}$ (lane 4). Then, the membranes were run on SDS-PAGE, incubated with TFF3, and analyzed by Western blot using anti-TFF3. Finally, co-immunoprecipitation assay was done (C). TFF3 purified (lane 1), HT-29 cells were incubated with TFF3 $(10 \mu \mathrm{g} / \mathrm{ml})$ by $2 \mathrm{~h}$. Then, cells lysates were immunoprecipitated with antibodies directed to PAR-2 (lanes 2-5). Immunoprecipitates were analyzed by Western blotting using anti-TFF3 antibody. TFF3 was only detected in the pellet fraction from cells lysates immunoprecipitated with anti-PAR-2, confirming that TFF3 interacts with PAR-2 in vitro (lane 2). In cells pre-treated with PAR-2 siRNA, TFF3 was not detected (lane 3). Negative controls were carried out: Cells lysates from HT-29 without immunoprecipitation with anti-PAR-2 (lane 4), and HT-29 cells lysates without TFF3 treatment (lane 5). (D-E) Silencing PAR-2 abolished TFF3 regulation of Cytokines and Defensins levels in cell culture supernatants.

and IL-6) and promotes human beta defensins (hBD2 and hBD4) expression in intestinal epithelial cells HT-29 (9). To confirm the involvement of PAR-2 in this process, HT-29 cells were treated with RNA interference (siRNA) as described above, and levels of cytokines and defensins were quantified by ELISA. HT-29 cells were grown in 6-well plates at $50 \%$ confluence and serum-starved for $24 \mathrm{~h}$. Cells were pre-incubated for $24 \mathrm{~h}$ with LPS $(1 \mu \mathrm{g} / \mathrm{ml})$, and then treated by $48 \mathrm{~h}$ with trefoil $10 \mu \mathrm{g} / \mathrm{ml}$. As shown in Figure 4, the levels of IL6 and IL8 (Fig. 4D) after treatment with LPS were significantly higher than in untreated cells. The treatment of HT-29 with TFF3 for $48 \mathrm{~h}$ after LPS treatment led to decrease of IL6 and IL8 similar to the basal levels. Finally, the treatment with TFF3 for $48 \mathrm{~h}$ after LPS incubation in cells pre-treated with PAR2 siRNA did not modify the cytokine levels. Together, the results demonstrates that IL6 and IL8 were down-regulated in HT-29 cells treated with TFF3 through PAR-2. Additionally, we directly measured the levels of these antimicrobial peptides in cells culture su- pernatants after $48 \mathrm{~h}$ incubation with TFF3 isolated from human breast milk. HT-29 cells with either LPS or TFF3 for $48 \mathrm{~h}$ led to increase of hBD2 and hBD4 concentrations at levels 3-fold higher than in untreated cells (Fig. 4E). In HT-29 cells pre-treated with siRNA, TFF3 did not modify the defensing levels. Together, the results demonstrated that cytokines and defensins were regulated by TFF3 through the protease activated receptor 2 .

Detecting TFF3-PAR-2 interactions by far Western blotting and co-immunoprecipitation

To further demonstrate the existence of interactions between TFF3 and PAR-2 receptors, far Western blot assay (Figs 4A-B) and co-immunoprecipitation (Fig. 4C) were done. In far Western blot assay, proteins in a cell lysate from HT-29 containing PAR-2 were firstly separated by SDS-PAGE, and transferred to a nitrocellulose membrane. Then, proteins in the membrane were denatured, renatured, blocked, and probed with purified TFF3. 
Finally, TFF3 proteins were detected on spots in the membrane where PAR-2 receptors were located because the TFF3 protein and PAR-2 together formed a protein complex. We found that TFF3 associated with PAR-2 (Fig. 4A, lane 1). Then, membranes were stripped and reprobed using standard immunoblotting to determine the position of the PAR-2 proteins on the membrane (Fig. 4A, lane 2). PAR-2 protein bands are shown around $44 \mathrm{kDa}$ (7). The higher bands are un-cleaved PAR-2 and the lower bands are cleaved PAR-2 as previously reported (14). Then, we tested if primary antibody anti-TFF3 (Santa Cruz Biotechnology, cat. No. sc-28927) bound non-specifically to cell lysate from HT29 through Western blot assay. We found that anti-TFF3 did not bind to any proteins contained in HT-29 (Fig. 4A, lane 3). Additionally, far Western blot assay in cells treated with siRNA was done (Fig 4B). We tested two siRNA concentrations (50 or 200 $\mathrm{nM}$,). In this assay, we showed that TFF3 associated with PAR2 (Fig. 4B, lane 1). Then, HT-29 cells treated with $200 \mathrm{nMof}$ PAR-2 siRNA produced a decrease between TFF3-PAR-2 association (Fig 4B, lane 4). This result suggested that PAR-2 bound to TFF3, and the specific PAR-2 knock-down inhibited the interaction between PAR-2 and TFF3. Finally, to further demonstrate that TFF3 binds to PAR-2, co-immunoprecipitation assay was done (Fig 4C). HT-29 cells were incubated with TFF3 (10 $\mu \mathrm{g} / \mathrm{ml}$ ) by $2 \mathrm{~h}$. Then, the cells were treated with lysis buffer and cell lysates were immunoprecipitated with antibodies directed to PAR-2 (lanes 2-5). Immunoprecipitated were analyzed by Western blotting using anti-TFF3 antibody. TFF3 was only detected in the pellet fraction from cells lysates immunoprecipitated with anti-PAR-2, confirming that TFF3 interacted with PAR-2 in vitro (lane 2). In cells pre-treated with PAR-2 siRNA, TFF3 was not detected (lane 3). Additionally, Figure 4C, lane 1 shows $10 \mu \mathrm{g} / \mathrm{ml}$ of TFF3 purified (Positive control). Finally, negative control were carried out: Cells lysates from HT-29 without immunoprecipitation with anti-PAR-2 (lane 4), and HT-29 cells lysates without TFF3 treatment (lane 5). Taken together, these data indicated that TFF3 bound to PAR2.

\section{Discussion}

Trefoil peptides are found along the gastrointestinal tract and play a central role in the physiology of the gut (15). In this work, we showed that TFF3 activated PAR-2 to produce intracellular signaling that resulted in cytokine and defensins regulation in HT-29 cells. Defensins are cysteine-rich, cationic peptides with $\beta$-pleated sheet configurations that are stabilized generally by three disulphide bonds. Human defensins are grouped in three subfamilies, the $\alpha$-, $\beta$ - and $\theta$-defensins. The beta-defensin family is produced by epithelial cells and plays an important role in mucosal defense against luminal microbes (16). The recent report showed that frog TFF2 activated protease-activated receptor 1 (PAR-1) to induce human platelet aggregation (6). Based on this result, we further tested the involvement of PAR-2 in human TFF3-promoted defensins and cytokines regulation (3). Two main mechanisms has been described for the activation of PAR-2: (1) by specific cleavage that unmask the receptor-acti- vating peptide sequence present in the extracellular $\mathrm{N}$-terminal domain of each PAR, leading to cell signaling via interaction of the exposed tethered ligand with the body of the receptor itself; and (2) by synthetic peptides, such as SLIGKV, that bind to the receptor, mimicking the actions of agonist proteases. In this work, we eliminated the first mechanism of activation by receptor proteolyisis because we isolated TFF3 from human breast milk without proteolytic activity (Fig. 1F). Subsequent, we speculated that the second activation mechanism was involved in this process. Several observations in our work suggested that TFF3 was a potential agonist of PAR-2. First, TFF3 isolated from human breast milk increased $\left(\mathrm{Ca}^{2+}\right) \mathrm{i}$ in HT-29 intestinal epithelial cells. Second, the responses to TFF3 were abolished by incubating cells with a specific PAR-2 antagonist peptide (FSLLRY, $200 \mu \mathrm{M}$ ) or pre-incubating cells with PTX, which is consistent with the idea that PAR-2 mediates the cellular response to TFF3. Moreover, the specific knockdown of PAR-2 receptors by siRNA blocked the activation of PAR-2 normally induced by both the agonist peptide (positive control) and TFF3.

We found that TFF3 isolated from human breast milk was more able to induce intracellular $\mathrm{Ca}^{2+}$ mobilization than PAR-2 agonist peptide, a mimic of the PAR-2 tethered ligand. The concentration $(1.25 \mathrm{nM}=10 \mu \mathrm{g} / \mathrm{ml})$ of TFF3 required was 160.000 -fold lower than PAR-2-agonist peptide $(200 \mu \mathrm{M})$ to produce similar $\mathrm{Ca}^{2+}$ mobilization response in intestinal epithelial cells HT-29 (Fig. 2). These results suggested that multiple binding sites might be involved in the interaction of TFF3 with PAR-2 to increase the binding affinity and/or activating efficiency. In this sense, because a lower concentration of TFF3 may activate PAR-2, we speculated that PAR-2 might be one of the natural intestinal receptors for TFF3 isolated from human milk. G-proteins coupled receptors (GPCR) often appear to assemble into dimmers, which have been shown to modulate ligand affinity and signal transduction (17). It also has been shown that dimmers of single-domain TFFs, such as TFF1, were biologically more potent than the monomers (18). TFF3 is usually a homodimmer and could act as a bivalent ligand. It is possible that TFF3 binds to and activates the dimeric form of PAR-2 to stimulate cell signaling. In this work, we showed a direct interaction between PAR-2 of intestinal epithelial cells and TFF3 isolated from human milk (Fig. 4). The TFF3 shares a completely conserved distinctive motif of six cysteine residues, which form three disulfide bonds and define the "trefoil" domain, which is also known as a 'P' domain (19). We speculated that every loops contained in trefoil factor 3 could play an important role in the binding of TFF3 and PAR-2.

There are several new findings of this study. First, we presented the head evidence of human putative intestinal receptor for TFF3 isolated from human milk. Second, PAR-2 knockdown by siRNA inhibited TFF3-induced intracellular signaling in intestinal epithelial cells HT-29. Third, the cytokine regulation and defensins expression were through PAR-2 expressed in intestinal cells. This work supported the hypothesis that during lactation, TFF3 secreted in human milk may activate intestinal epithelial cells through PAR-2 receptors, which in turn induces hBD2 and hBD4 expression and cytokine regulation. 


\section{References}

1. Lönnerdal B. Bioactive proteins in human milk: mechanisms of action. J Pediatr 2010; 156: S26-30.

2. Hettinga K, van Valenberg H, de Vries S, Boeren S, van Hooijdonk T, van Arendonk J, Vervoort J. The host defense proteome of human and bovine milk. PLoSOne 2011; 6 (4): e19433.

3. Barrera GJ, Sanchez G, Gonzalez JE. Trefoil factor 3 isolated from human breast milk downregulates cytokines (IL8 and IL6) and promotes human beta defensin (hBD2 and hBD4) expression in intestinal epithelial cells HT-29. Bosn J Basic Med Sci 2012; 12 (4): 256-264.

4. Barrera Roa GJ, Sanchez T, Gonzalez JE. Trefoil factor 3 (TFF3) expression is regulated by insulin and glucose. J Health Sci 2013; 3 (1): 1-12.

5. Yong Z, Lin W, Yong S, Guang-ping L, Dan W et al. Kinetic Characterization of an INtestinal Trefoil Factor Receptor. PLoS ONE 2013; 8 (9): e74669. doi:10.1371/journal.pone.0074669.

6. Zhang Y, Yu G, Wang Y, Xiang Y, Gao Q, Jiang P, Zhang J, Lee W, Zhang Y. Activation of protease-activated receptor (PAR) 1 by frog trefoil factor (TFF) 2 and PAR4 by human TFF2. Cell Mol Life Sci 2011; 68 (22): 3771-3780.

7. Jarry A, Dorso L, Gratio V, Forgue-Lafitte ME, Laburthe M, Laboisse CL, Darmoul D. PAR-2 activation increases human intestinal mucin secretion through EGFR transactivation. BiochemBiophys Res Commun 2007; 364 (3): 689-694.

8. Hung CF, Lu KC, Cheng TL, Wu RH, Huang LY, Teng CF, Chang WT. A novel siRNA validation system for functional screening and identification of effective RNAi probes in mammalian cells. BiochemBiophys Res Commun 2006; 346 (3): 707-720.

9. Wu Y, Li Q, Chen XZ. Detecting protein-protein interactions by Far Western blotting. Nat Protoc 2007; 2( 12): 3278-3284.
10. Barrera G, Sanchez TG, Rivas A, Flores C, Gonzalez JE. Increased expression and levels of human $\beta$ defensins (hBD2 and hBD4) in adults with dental caries. J Health Sci 2013; 3 (2): 1-10.

11. Scarborough RM. Protease-activated receptor- 2 antagonists and agonists. Curr Med Chem Cardiovasc Hematol Agents 2003; 1: 73-82.

12. Al-Ani B, Saifeddine M, Wijesuriya SJ, Hollenberg MD. Modified proteinase-activated receptor-1 and -2 derived peptides inhibit proteinaseactivated receptor-2 activation by trypsin. J Pharmacol Exp Ther 2002; 300: 702-708.

13. Kawabata A, Matsunami M, Sekiguchi F. Gastrointestinal roles for proteinase-activated receptors in health and disease. Br J Pharmacol 2008; 153: S230-S240.

14. Lin KW, Park J, Crews AL, Li Y, Adler KB. Protease-activated receptor-2 (PAR-2) is a weak enhancer of mucin secretion by human bronchial epithelial cells in vitro. Int J Biochem Cell Biol 2008; 40: 1379-1388.

15. Tran CP, Cook GA, Yeomans ND, Thim L, Giraud AS. Trefoil peptide TFF2 (spasmolytic polypeptide) potently accelerates healing and reduces inflammation in a rat model of colitis. Gut 1999; 44: 636-642.

16. Ganz T. The role of antimicrobial peptides in innate immunity. Integr Comp Biol 2003; 43: 300-304.

17. Lohse MJ. Dimerization in GPCR mobility and signaling. Curr Opin Pharmacol 2010; 10: 53-58.

18. Williams MA, Westley BR, May FE, Feeney J. The solution structure of the disulphide-linked homodimer of the human trefoil protein TFF1. FEBS Lett 2001; 493: 70-74.

19. Polshakov VI, Williams MA, Gargaro AR, Frenkiel TA, Westley BR, Chadwick MP, May FE, Feeney J. High-resolution solution structure of human pNR-2/pS2: a single trefoil motif protein. J Mol Biol 1997; 267: 418-432. 